RESEARCH ARTICLE

\title{
Lifestyle, Diet and Body Mass Index in Offspring of Women with Pregestational and Gestational Diabetes
}

\author{
Nurah M Hammoud ${ }^{1,2^{*}}$, Harold W de Valk ${ }^{2}$, Lenie van Rossem ${ }^{3}$, Geertje W Dalmeijer ${ }^{3}$, \\ Douwe H Biesma ${ }^{2}$, Jan M Wit ${ }^{4}$, Maarten Rijpert ${ }^{5}$ and Gerard HA Visser ${ }^{1}$
}

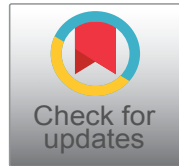

\author{
${ }^{1}$ Department of Obstetrics, Division Woman \& Baby, University Medical Center Utrecht, The Netherlands \\ ${ }^{2}$ Department of Internal Medicine and Infectious Diseases, University Medical Center Utrecht, The Netherlands \\ ${ }^{3} J u l i u s$ Center for Health Sciences and Primary Care, University Medical Center Utrecht, The Netherlands \\ ${ }^{4}$ Department of Pediatrics, Leiden University Medical Center, Leiden, The Netherlands \\ ${ }^{5}$ Department of Neonatology, Emma Children's Hospital, Academic Medical Center, Amsterdam, The Netherlands
}

*Corresponding author: NM Hammoud, MD PhD, Department of Obstetrics, Division Woman \& Baby and Department of Internal Medicine and Infectious Diseases, University Medical Center Utrecht, Heidelberglaan 100, Huispostnummer KE.04.123.1, P.O. Box 85090, 3508 AB Utrecht, The Netherlands, Tel: +31-641527955, Fax: +31-88-75-554-30

\begin{abstract}
Purpose: Offspring from women with diabetes have an increased risk for childhood obesity, which may be related to the abnormal intrauterine environment, genetic imprinting or current diet and lifestyle. We analyzed whether diet and lifestyle differ between offspring from women with either type 1 , type 2 or gestational diabetes.

We collected completed questionnaires from parents of 51 offspring from women with type 1 diabetes (ODM1), 21 of women with type 2 diabetes (ODM2) and 87 of women with gestational diabetes (OGDM)

Methods: All women with a pregnancy complicated by type 1 , type 2 or gestational diabetes, who delivered between 1990 and 2006 in a tertiary center were contacted for this retrospective study. We compared offspring diet and lifestyle between offspring of maternal diabetes.

Results: The prevalence of maternal overweight/obesity before pregnancy was significantly higher in women with DM2 compared to GDM and DM1; their offspring had a slightly higher incidence of overweight at follow-up as compared to the other groups. ODM2 skipped breakfast more often and were less frequently a member of a sports club but consumed less snacks. Intake of fruit, vegetables and sugar containing drinks were comparable between the groups. ODM2 parents judged their offspring as being more vulnerable and less healthy compared to peers, whilst ODM1 and OGDM parents report their children's' health comparable to peers.
\end{abstract}

Conclusion: Lifestyle and dietary intake in childhood can be affected by different environmental and lifestyle factors. In this relatively small study offspring from women with type 2 diabetes seem to have a less healthy diet and lifestyle with might contribute to their increased risk of development of obesity later in life. Larger studies are needed to provide possible targeted interventions for prevention of childhood overweight/obesity in these children.

\section{Keywords}

Offspring obesity, Offspring of diabetic pregnancies, Diet, Lifestyle, Childhood nutrition

\section{List of Abbreviations}

BMI: Body Mass Index; BW: Birth weight; cTH: Conditional Target Height; IOTF: International Obesity Task Force; LGA: Large for Gestational Age; ODM1: Offspring of Type 1 Diabetes Pregnancies; ODM2: Offspring of Type 2 Diabetes Pregnancies; OGDM: Offspring of Gestational Diabetic Pregnancies; OGTT: Oral Glucose-Tolerance Test; SD: Standard Deviation; SDS: Standard Deviation Score

\section{Introduction}

Children of women with type 1 , gestational and especially type 2 diabetes mellitus during pregnancy are at increased risk of developing obesity during childhood [1-3]. In a longitudinal cohort of Pima Indians, offspring of pregnancies complicated by diabetes have an odds

\footnotetext{
Citation: Hammoud NM, Valk HW, Rossem LV, Dalmeijer GW, Biesma DH, et al. (2018) Lifestyle, Diet and Body Mass Index in Offspring of Women with Pregestational and Gestational Diabetes. Int J Pediatr Res 4:037. doi.org/10.23937/2469-5769/1510037

Accepted: October 03, 2018: Published: October 05, 2018

Copyright: () 2018 Hammoud NM, et al. This is an open-access article distributed under the terms of the Creative Commons Attribution License, which permits unrestricted use, distribution, and reproduction in any medium, provided the original author and source are credited.
} 
ratio of 3.7 to develop type 2 diabetes later in life [1]. Up to $89 \%$ of offspring (age 2-19 years) of mothers with type 2 diabetes are overweight and $30-40 \%$ of offspring (age 18-27 years) of mothers with type 1 diabetes or gestational diabetes [2,3]. In our recent longitudinal study, we showed that the risk of overweight is highest for children of women with type 2 diabetes who were born large-for-gestational age (LGA), followed by nonLGA infants of type 2 diabetic women. Childhood obesity was lowest in offspring from women with gestational diabetes (GDM) [4,5]. Childhood obesity in children from pregnancies complicated by maternal diabetes is hypothesized to be due to genetic imprinting, effects of an abnormal intrauterine environment (with a relatively overnourished fetus and subsequent changes in adipose tissue as well as energy regulation that echoes throughout their lives $[6,7])$, and/or current diet and lifestyle. Also, maternal BMI has been shown to be a significant determinant of childhood BMI [8-12], with hyperglycemia as further contributing factor $[3,11]$.

In the postnatal period, nutritional and other lifestyle habits from parents are easily transmitted to children, which may contribute to the development of childhood adiposity, together with overweight parents not recognizing adiposity in their offspring [13]. Other lifestyle habits may also contribute to a higher offspring BMI, such as physical activity, sleep and screen time [14-19].

To the best of our knowledge there is no published literature on diet and lifestyle in offspring from diabetic pregnancies. The aim of this study was to assess differences in diet and lifestyle between offspring from women with type 1 (ODM1), type 2 (ODM2) and gestational diabetes (OGDM). Furthermore, we studied the overall health perception in these groups as judged by their parents as an indication of their wellbeing.

\section{Methods}

\section{Study design and population}

All women with a pregnancy complicated by type 1 , type 2 or gestational diabetes mellitus who gave birth in the University Medical Center (UMC), Utrecht, the Netherlands, between 1990 and 2006 were contacted to participate in this retrospective study. Parents were asked to complete a questionnaire by (e)mail including questions regarding their offspring diet, lifestyle, anthropometric data, parental health and ethnicity. If parents had multiple children that were born in the study period, the questionnaire was completed for each child. Offspring weight and height were retrieved from parental records of the Dutch infant welfare centers. The children are measured in the school health service at 5.5, 11 and 13 years, with a range of $1-2$ years around these ages. For this study we used the most recent measurements, closest to the time of completion of the questionnaire. Parents were asked to report on the current status of their child's intake, screen time and physical activity, at the time the questionnaire was completed.

All women with type 1 and type 2 diabetes had a singleton pregnancy, whereas in the GDM group 4 dichorionic diamniotic twin pairs (i.e. most likely dizygotic) were included. One infant with trisomy 21 was excluded from the OGDM subgroup, because of the known shorter stature and parental influence on lifestyle in children with Down's syndrome [20]. There were no infants with major structural malformations in the study population. Gestational diabetes was diagnosed using a 75-g oral glucose tolerance test in 67 (77\%) of cases; the other patients were diagnosed through elevated fasting glucose levels or an abnormal glucose profile. All women with type 1 and type 2 diabetes mellitus were treated with insulin during their pregnancy; 46 (54\%) of women with gestational diabetes were treated with insulin. Maternal characteristics during pregnancy and pregnancy outcome, including birthweight, were retrieved from their medical records. The medical ethics committee of the University Medical Center Utrecht approved this study.

\section{Anthropometrics}

Birthweight (BW) Z-score was calculated as (BW minus mean BW for gender, parity and gestational age)/ SD, based on Dutch reference data [21]. Large for gestational age (LGA) was defined as a $B W \geq 90$ th percentile corrected for gestational age, sex, and parity [21]. $\mathrm{BMI}$ was calculated as weight $(\mathrm{kg}) /$ height $(\mathrm{m})^{2}$ and expressed as SDS (standard deviation score) according to age and gender specific Dutch reference data $[22,23]$. The 1980 nation-wide growth study [22], in which SDS 0 equals the age- and gender-specific mean of the 1980 Dutch reference population is used as the Dutch normative standard for BMI, thus reflecting a degree of overweight and obesity in the study group. The latest Dutch population-based study on childhood BMI was in 2009 [23]. Overweight and obesity were calculated based on the International Obesity Task Force (IOTF) cut-off values [24]. Conditional target height (cTH) was calculated from parental heights according to Hermanussen \& Cole [25] adapted to Dutch growth standards [26]. Software available from the Dutch Growth Research Foundation was used to calculate BMI SDS (@Growth Analyser 3.5).

\section{Dietary and lifestyle assessment}

The questionnaire was adapted from The Prevention and Incidence of Asthma and Mite Allergy (PIAMA) study [27] and included 46 different questions on overall health perception, food intake, physical activity and school grades of offspring. Additionally, questions included parental information regarding their own current height and weight, chronic diseases, educational status, ethnic origin, current full-/or part-time job and duration of breast-feeding in the neonatal period for each infant. 
For diet, 7 questions were included in the questionnaire, which inquired on the frequency of consumption of breakfast, fruits, vegetables, snacks, sugar containing juice and fruit juice in offspring. There were five answering categories (ranging from "never" to "more than 2 or 3 servings a day"), the answer to the questions on the number of weekdays that breakfast, fruits and vegetables were consumed could range from "never" to "every day of the week". For the analyses, these answer options were translated to 3 scale categorical variables for breakfast, fruits, vegetables: Never (1), 1-3 days a week (2), $\geq 4$ days a week (3). The amount of servings of juice and snacks a day were also categorized into the following 3 categories: none (1), 1/2-11/2 servings per day (2), $\geq 2$ servings per day (3).

For physical activity in offspring 5 questions were included, which inquired on how many days a week children would walk or cycle to school and play outside (ranging from "never" to "every day of the week"). Also, information on the hours spent playing outside per day and screen time on a daily basis was included (ranging from "30 minutes or less" to " 4 hours or more"). Membership of a sports club was included and categorized ("yes" or "no"). For analyses, the answers were translated to a 3 scale categorical variable for walking/cycling to school and playing outside: Never (1), 1-3 or 1-2 days a week (2), $>3$ or $\geq 3$ days a week (3), respectively. Hours spent playing outside and screen time were also translated into the following 3 or 4 categories: $\leq 1$ hour or $\leq 30$ minutes per day (1), $1-2$ hours per day or $1 / 2$ hour1 hour/day (2), $\geq 3$ or $1-2$ hours per day (3), $>2$ hours screen time per day (4).

We asked the parents for the overall impression of their offspring's health and vulnerability compared to their peers. Response options included 5 categories (ranging from "excellent to generally healthy or vulnerable perception" to "moderate to unhealthy or not vulnerable perception"). For the analyses, the answer options were recoded to 2 categories: (1) Healthy (if always or mostly healthy) or (2) Less healthy; the same 2 categories were applied to vulnerability. Finally, the impression of stressfulness of the offspring's life as judged by their parent was scaled from 0 to 10 (with " 10 " being most stressful).

\section{Statistical analysis}

We compared dietary and lifestyle characteristics among different diabetes groups.

For continuous characteristics, we compare the mean (SD) for each group, or in the case of non-normal-

Table 1: Parental and offspring characteristics.

\begin{tabular}{|c|c|c|c|c|}
\hline & ODM1 & ODM2 & OGDM & $\mathbf{P}$ \\
\hline & $n=51$ & $n=21$ & $n=87$ & \\
\hline \multicolumn{5}{|l|}{ ODM characteristics } \\
\hline Age at follow-up (years) & $10.9 \pm 2.6$ & $9.2 \pm 3.7$ & $9.7 \pm 3.0$ & $<0.05$ \\
\hline BMI $\left(\mathrm{kg} / \mathrm{m}^{2}\right) \Upsilon$ & $17.4(3.7)$ & $17.1(5.7)$ & $17.0(3.3)$ & 0.14 \\
\hline BMI SDS & $0.6 \pm 1.25$ & $1.2 \pm 1.47$ & $0.6 \pm 1.32$ & 0.12 \\
\hline Overweight or obese (\%) & $8(16)$ & $8(38)$ & $17(20)$ & 0.10 \\
\hline Height (cm) & $149 \pm 19$ & $138 \pm 25$ & $141 \pm 20$ & $<0.05$ \\
\hline cTH (cm) & $176 \pm 7.8$ & $175 \pm 7.3$ & $176 \pm 7.3$ & 0.10 \\
\hline \multicolumn{5}{|l|}{ Neonatal characteristics } \\
\hline Gestational age at birth (weeks) $\mathbb{T}$ & $38(2)$ & $38(1)$ & $39(2)$ & $<0.05$ \\
\hline Birthweight (gr) ף & $3535(915)$ & $3730(545)$ & $3555(738)$ & 0.63 \\
\hline Large for gestational age (\%) & $24(47)$ & $7(33)$ & $23(26)$ & $<0.05$ \\
\hline Breastfed (\%) & $38(75)$ & $12(57)$ & $53(61)$ & 0.20 \\
\hline \multirow[t]{2}{*}{ Breastfed $\geq 6$ months $(\%)^{*}$} & $7(18)$ & $4(33)$ & $18(34)$ & 0.24 \\
\hline & $n=33$ & $n=13$ & $n=72$ & \\
\hline \multicolumn{5}{|l|}{ Maternal characteristics ${ }^{* *}$} \\
\hline Age at child birth (years) & $33.3 \pm 3.4$ & $32.6 \pm 5.4$ & $33.6 \pm 4.3$ & 0.82 \\
\hline Caucasian (\%) & $33(100)$ & $10(77)$ & $62(86)$ & $<0.05$ \\
\hline Education university of applied sciences (\%) & $17(52)$ & $3(23)$ & $23(32)$ & $<0.05$ \\
\hline \multicolumn{5}{|l|}{ BMI before pregnancy } \\
\hline BMI $\left(\mathrm{kg} / \mathrm{m}^{2}\right) \mathrm{T}$ & $24.0(3.8)$ & $29.4(7.8)$ & $26.2(7.6)$ & $<0.05$ \\
\hline BMI classification $(\%)$ & & & & $<0.05$ \\
\hline Normal weight & $22(67)$ & $2(15)$ & $29(40)$ & \\
\hline Overweight $(\mathrm{BMI}>25 /<=30)$ & $8(24)$ & $5(39)$ & $24(33)$ & \\
\hline Obese (BMI > 30) & $3(9)$ & $6(46)$ & $19(27)$ & \\
\hline \multicolumn{5}{|l|}{ Paternal characteristics } \\
\hline Current BMI $\left(\mathrm{kg} / \mathrm{m}^{2}\right)$ I & $24.7(5.0)$ & $27.2(5.2)$ & $25.8(3.7)$ & 0.11 \\
\hline Diabetes (currently, any type) (\%) & $2(4)$ & 0 & $1(1)$ & 0.41 \\
\hline
\end{tabular}

Values are $\mathrm{n}(\%)$ or mean \pm SD or median (interquartile range) in skewed data ๆ; "no. missing values for ODM1 13; ODM2 9; OGDM 34; *Eldest infant of the mother born our center (e.g. primiparous women); BMI SDS based on values of Dutch nationwide growth study [22]. 
ity, median (IQR) for each diabetes group. Differences between diabetes groups are tested with ANOVA. For categorical variables, we compared the percentages for each group. Differences between diabetes groups are tested with Chisquare test.

Data were analyzed using IBM ${ }^{\circledR}$ SPSS Statistics version 23.0 for Mac.

\section{Results}

One hundred and fifty ODM1, 70 ODM2 and 478 OGDM were identified and contacted. A completed questionnaire was received from 51 (34\%) ODM1; 21 (30\%) ODM2 and 87 OGDM (21\%) from 33 mothers with type 1, 13 mothers with type 2 and 72 mothers with gestational diabetes during pregnancy; mothers included up to 2 children in the study. Age and BMI at baseline from mothers with type 1 or type 2 diabetes mellitus who participated in this study were comparable to those of the women who did not. For mothers with gestational diabetes the ethnicity was different between responders and non-responders, with more Dutch women in the responders group, and more women from non-native Dutch (mainly Mediterranean) origin in the non-responder group. ODM and parental characteristics are summarized in Table 1.

Mean offspring age of ODM1, ODM2 and OGDM was $10.9,9.2$ and 9.7 years, respectively $(p<0.05)$ with 55,46 and $47 \%$ females in these groups. BMI in ODM1, ODM2 and OGDM was $17.4,17.0$ and $17.1 \mathrm{~kg} / \mathrm{m}^{2}$, respectively (NS). The prevalence of overweight or obese children $\left(\mathrm{BMI}>25 \mathrm{~kg} / \mathrm{m}^{2}\right)$ was 16,38 and $20 \%$ respectively (NS). ODM1 were taller compared to ODM2 and OGDM (Table 1), but the conditional target height for the groups were comparable.

The gestational age at birth was 39 weeks in OGDM and 1 week shorter in ODM1 and ODM $2(p<0.05)$. The birthweight did not differ between the groups (3535, 3730, $3555 \mathrm{gr}$; NS), but there were more LGA neonates in ODM1, compared to ODM2 and $\operatorname{OGDM}(47,33,26 \%$; $p$ $<0.05)$. Breastfeeding rates were comparable between the 3 groups (ODM1 75\%, ODM2 57\%, OGDM 61\%; NS); and breastfeeding rates for longer than 6 months were not statistically different $(18,33,34 \%$, respectively; (NS; Table 1).

Maternal age did not differ between the groups and was approximately 33 years. Mothers with ODM 1 and OGDM were more often of Caucasian descent (100, $86 \%$, respectively), compared to ODM2 $(77 \%)(p<0.05)$. $50 \%$ of mothers of ODM 1 had a degree in university of applied sciences, versus 23 and $23 \%$ in mothers from ODM2 and OGDM ( $p<0.05)$. Mothers of OGDM2 had a higher pre-pregnancy BMI $\left(29.4 \mathrm{~kg} / \mathrm{m}^{2}\right)$ compared to ODM1 and OGDM with also a higher percentage of overweight/obese mothers (85\%) (Table 1). Current paternal BMI was comparable between the groups (24.7, $27.2,25.8 \mathrm{~kg} / \mathrm{m}^{2}$; NS). Only a few fathers were diag- nosed with diabetes at the time of completion of the questionnaire (Table 1).

\section{Possible causes of adiposity}

In Table 2, the results of the questionnaire are shown. Significantly more ODM2 had breakfast less than 4 times

Table 2: Dietary and lifestyle assessment.

\begin{tabular}{|c|c|c|c|c|}
\hline & ODM1 & ODM2 & OGDM & $\mathbf{P}$ \\
\hline & $n=51$ & $n=21$ & $n=87$ & \\
\hline \multicolumn{5}{|l|}{ Diet } \\
\hline Breakfast & & & & $<0.05$ \\
\hline Never & $1(2)$ & 0 & 0 & \\
\hline 1-3 times a week & 0 & $4(19)$ & $1(1)$ & \\
\hline$>3$ times a week & $50(98)$ & $17(81)$ & $86(98)$ & \\
\hline Vegetables & & & & 0.37 \\
\hline Never & 0 & 0 & 0 & \\
\hline 1-3 times a week & 0 & $1(5)$ & $2(2)$ & \\
\hline$>3$ times a week & $51(100)$ & $20(95)$ & $85(98)$ & \\
\hline Fruit intake & & & & 0.35 \\
\hline Never & $3(6)$ & $1(5)$ & $2(2)$ & \\
\hline 1-3 times a week & $6(12)$ & $4(19)$ & $6(7)$ & \\
\hline$>3$ times a week & $42(82)$ & $16(76)$ & $79(91)$ & \\
\hline Amount of fruit & & & & 0.43 \\
\hline None & $3(6)$ & $1(5)$ & $3(3)$ & \\
\hline $1 / 2-1 \frac{1}{2}$ per day & $40(78)$ & $13(62)$ & $69(79)$ & \\
\hline$=>2$ per day & $8(16)$ & $7(33)$ & $15(17)$ & \\
\hline Fruit juice & & & & 0.57 \\
\hline None & $21(41)$ & $8(38)$ & $38(44)$ & \\
\hline 1-2 servings per day & $30(59)$ & $12(57)$ & $48(55)$ & \\
\hline$>2$ servings per day & 0 & $1(5)$ & $1(1)$ & \\
\hline Sugar containing drinks & & & & 0.67 \\
\hline None & $5(10)$ & $2(10)$ & $4(5)$ & \\
\hline 1-2 servings per day & $34(67)$ & $12(57)$ & $59(67)$ & \\
\hline$>2$ servings per day & $12(23)$ & $7(33)$ & $24(28)$ & \\
\hline Snacking between meals & & & & $<0.05$ \\
\hline Sometimes (< 1/day) & $2(4)$ & $6(28)$ & $10(12)$ & \\
\hline Once or twice a day & $43(84)$ & $13(62)$ & $63(72)$ & \\
\hline More than twice a day & $6(12)$ & $2(10)$ & $14(16)$ & \\
\hline \multicolumn{5}{|l|}{ Lifestyle } \\
\hline Walking/cycling to school ${ }^{*}$ & & & & 0.44 \\
\hline Never & $3(6)$ & $2(10)$ & $13(15)$ & \\
\hline 2/5 times per week & $1(2)$ & $1(5)$ & $4(5)$ & \\
\hline$\geq 3 / 5$ times per week & $47(92)$ & $17(85)$ & $68(80)$ & \\
\hline Play outside & & & & 0.18 \\
\hline$<1$ day a week & $7(14)$ & $2(10)$ & $4(5)$ & \\
\hline 1-3 times a week & $11(21)$ & $8(38)$ & $20(23)$ & \\
\hline$>3$ times a week & $33(65)$ & $11(52)$ & $63(72)$ & \\
\hline Hours spent outside ${ }^{* *}$ & & & & 0.38 \\
\hline Max. 1 hour & $3(6)$ & $3(14)$ & $11(13)$ & \\
\hline $1-2$ hours & $36(71)$ & $14(67)$ & $48(56)$ & \\
\hline Three hours or more & $12(24)$ & $4(19)$ & $27(31)$ & \\
\hline Screen time hours ${ }^{* *}$ & & & & 0.09 \\
\hline Max. 30 minutes/day & $7(14)$ & $7(35)$ & $26(30)$ & \\
\hline $1 / 2$ hour-1 hour/day & $26(50)$ & $7(35)$ & $31(36)$ & \\
\hline 1-2 hours/day & $8(16)$ & $3(15)$ & $22(25)$ & \\
\hline$>2$ hours/day & $10(20)$ & $3(15)$ & $8(9)$ & \\
\hline Member of sports club (yes) & $46(90)$ & $14(67)$ & $73(84)$ & $<0.05$ \\
\hline
\end{tabular}

\section{Diet}

\section{Breakfast}

Vegetables

Fruit intake

Neve

Amount of fruit

None

$=>2$ per day

Fruit juice

1-2 servings per day

servings per day

None

1-2 servings per day

$>2$ servings per day

Snacking between meals

( 1 day)

More than twice a day

Walking/cycling to school

Never

Play outside

$>3$ times a week

Hours spent outside

Max. 1 hour

Three hours or more

Screen time hours

Max. 30 minutes/day

$1 / 2$ hour-1 hour/day

1-2 hours/day 
Table 3: Health impression as judged by the parents.

\begin{tabular}{|l|l|l|l|l|}
\hline & ODM1 & ODM2 & OGDM & P \\
\hline & $n=51$ & $n=21$ & $n=87$ & \\
\hline Normal health $^{*}$ & $50(98)$ & $17(85)$ & $86(99)$ & $<0.05$ \\
\hline Not vulnerable $^{* *}$ & $47(92)$ & $12(75)$ & $78(94)$ & $<0.05$ \\
\hline Stressful life $^{* *}$ & $3.4 \pm 2.3$ & $4.2 \pm 2.9$ & $3.1 \pm 2.5$ & 0.17 \\
\hline
\end{tabular}

Values are $\mathrm{n}(\%)$ or mean \pm SD: "no. missing values for ODM2 1; "no. missing values for ODM2 5; OGDM 4;

${ }^{* * *}$ no. missing values for ODM1 1; ODM2 3

a week, as compared to ODM1 and OGDM. Vegetable, fruit, sugar containing drinks or fruit juice consumption were comparable between the groups. ODM2 consumed significantly less snacks between meals (62\%) compared to ODM1 (84\%) and ODM2 (72\%, p < 0.05). Walking or cycling to school, the amount of hours playing outside and screen time per day were comparable between the groups (NS). Significantly less ODM2 (67\%) were member of a sports club compared to ODM1 (90\%) and OGDM (84\%).

\section{Possible consequences of adiposity}

The impression of health and vulnerability of the child, as judged by their parents, is presented in Table 3. Parents of ODM2 were less positive about their child's health compared to parents of ODM1 and OGDM. Most parents of ODM1 and OGDM judged their children to be generally resistant (i.e. judging their offspring as less vulnerable), whereas only $75 \%$ of the parents of ODM2 judged their children as generally resistant. There were no significant differences between the groups regarding the degree of stressfulness of life.

\section{Discussion}

This is the first study on lifestyle and diet in offspring from diabetic pregnancies. We found some interesting differences in lifestyle and diet between offspring from women with type 2 diabetes on the one hand and type $1 /$ gestational diabetes on the other hand. ODM2 more often skipped breakfast, snacked less and were less often a member of a sport club and their parents were less positive about their health. Prevalence of childhood overweight/obesity was twice as high in ODM2 as compared to ODM1/OGDM, although this difference was not statistically significant. The latter may be due to the low number of ODM2. In larger studies, including ours, $\mathrm{BMI}$ at follow-up was significantly higher in ODM2 [2-5].

Several findings may explain a higher prevalence of overweight/obesity in ODM2. The prevalence of maternal overweight/obesity, which was highest in the ODM2 group, may be one factor. Preexisting maternal obesity has previously been related to the differences in the offspring's BMI SDS trajectories $[8,11,10,28]$. Unfortunately, there are no studies on diet and lifestyle of offspring from women with diabetes, but there is considerable knowledge regarding non-diabetic offspring, which might help explain the differences in BMI, lifestyle and diet in this group. In relatively younger ODM2 there was a lower attendance of sport clubs (as a proxy for less physical activity), and a higher percentage of skipping breakfast as a reflection of a non-balanced diet. The latter has previously been related to a higher prevalence of childhood obesity in children of elementary school age $[29,30]$. Moreover, participation in school breakfast programs, in which children regularly consume (school) breakfast, is associated with a lower BMI [31]. Interestingly however, in ODM2 a lower consumption of snacks was reported. This is in line with previous studies that showed less snacking in overweight/obese children [32], suggesting that sports activity is more important than total caloric intake, but it may also reflect that (obese) mothers do not adequately recall their infant's diet and could therefore be the result of underestimation by parents. Additionally, regarding consumption of snacks, the Netherlands Nutrition Centre encourages a maximum of 4 snacks a day, to reduce overeating. Copying of parental habits could also play a part in offspring obesity, and it has been shown that intake of fruit and vegetables is correlated between children and mothers, with obese children often consuming less of these products [33]. Studies on parental restriction of offspring diet have shown conflicting results, with a desirable effect in parental restriction leading to less consumption of 'unhealthy food-items' in toddlers and adolescents regarding soft drink consumption with a decrease in BMI SDS of offspring [34,35], whilst other studies showed a paradoxically increased consumption of the restricted items and a higher BMI SDS associated with strict parental regulation of healthy items [36,37]. Higher maternal BMI is associated with less dietary restriction [37]. On the other hand, higher maternal educational status stimulates physical activity in offspring, restricts sedentary time and stimulates healthy intake in children [37]. It may be that restrictive parental feeding practices have played a role in our study, but questions relating to this issue were not included in the questionnaire.

Also other lifestyle factors are known to be associated with risk of overweight, such as screen time [17] and short sleeping time [14]. The hours of daily screen time are associated with childhood BMI between the ages of 5-10 years and video games are associated with elevated blood pressure and lipids in obese children aged 14-18 years [15-18]. Children who spend more time viewing TV appear to have a poorer diet, with higher intakes of sugar, fast food, snacks and processed meats with lower intakes of fruit and vegetables [19]. It has been estimated that >1-hour screen time per day contributed approximately $17 \%$ to being overweight [17]. In contrast, an active lifestyle stimulates physical activity and fewer parental restrictions in sedentary time [37] and this would likely prevent overweight/obesity. Interestingly, we did not find a difference in screen time or active lifestyle (walking/cycling to school, play outside) between ODM2 and ODM1/OGDM, suggesting that maternal obesity and the lack of regular breakfast may be of greater importance in the onset of childhood overweight/obesity. 
Previous findings regarding the effects of breast-feeding on the offspring's BMI in diabetic women are inconclusive $[38,39]$. Given the fact that the rate and duration of breast-feeding did not differ between ODM2 and GDM (in contrast to childhood overweight/obesity), it might be that breast-feeding is no longer of influence when taking into account the type of maternal diabetes on the development of overweight in these children.

\section{Limitations}

Although a considerable number of children were born in our tertiary center during the study period, the traceability of parents was difficult. Even though maximum efforts were made to contact all parents, a response rate of only $20 \%$ was reached for the ODM. Therefore, the numbers in this study are relatively small and this hampers precision of the results and additional analysis of, for example, the effects of diet and lifestyle on BMI SDS growth patterns. A prospective cohort study might improve inclusion and follow-up of these children. Furthermore, when using questionnaires one cannot rule out some degree of information or recall bias. Attendance of child-care could attribute to a great variance in intake. Toddlers attending daycare have an energy intake in the upper ranges of the recommended intake [40]. Unfortunately, we do not know how many children in our population attended child-care. Also, given the relatively low number of cases included we were unable to assess relationships between BMI of the children and their diet and lifestyle.

\section{Recommendations and summary}

Our finding of a trend towards a higher prevalence of childhood overweight/obesity in ODM2 necessitates the need for preventive strategies. It has been shown that parental feeding practices are linked to dietary habits and food intake, not only during childhood, but also in adult life [41]. Early intervention may consist of for example family-based behavioral treatments to reduce total energy intake [35] or increasing parental concern on offspring diet through intensive counseling of obese parents [13]. Parents should stimulate towards an active lifestyle, because this also stimulates physical activity in offspring [37]; moreover, a reduction of restrictive parental feeding practices is advised [35].

In summary, this is the first study on lifestyle and diet in offspring from diabetic women. ODM2 had an almost twice as high incidence of childhood overweight/ obesity compared to ODM1 and GDM (NS), which was related to maternal overweight, skipping breakfast, less snacking and lower membership of a sports club. These results indicate that the higher prevalence of overweight/obesity in ODM2 may partly be due to parental lifestyle influences, which enables the design of preventive strategies. Obviously larger (prospective) studies are necessary to improve childhood health.

\section{Declarations}

\section{Details of ethical approval}

Ethics approval was granted by the Medical Ethics Committee at the University Medical Center, Utrecht in the Netherlands (application number 13/179, reference number WAG/om/13/053639) on the 09th of April 2013.

\section{Consent for publication}

Not applicable.

\section{Availability of data and materials}

The datasets used and/or analysed during the current study are available from the corresponding author on reasonable request.

\section{Competing interests}

The authors declare that they have no competing interests.

\section{Funding}

The authors have nothing to disclose.

\section{Authors' contributions}

N.H., H.V., L.R., G.D., D.B., J.M.W., M.R., G.V. contributed to conception and design of study; N.H. performed acquisition of data, and analysis and interpretation of data, drafted article; L.R., G.D., performed analysis and interpretation of data; H.V., L.R., G.D., D.B., J.M.W., M.R., G.V. revised draft(s) critically for important intellectual content. N.H., H.V., L.R., G.D., D.B., J.M.W., M.R., G.V. gave final approval of the version to be published. N.M. Hammoud is responsible for the integrity of the work as a whole.

\section{Acknowledgments}

We would like to thank all the parents and our trial manager Bianca Silvius for their cooperation in making this study possible. We would also like to thank Prof $\mathrm{Dr}$ H.A. Smit, from the Julius Center for Health Sciences and Primary Care for her help with the PIAMA questionnaire.

\section{References}

1. Dabelea D, Hanson RL, Lindsay RS, Pettitt DJ, Imperatore G, et al. (2000) Intrauterine exposure to diabetes conveys risks for type 2 diabetes and obesity: A study of discordant sibships. Diabetes 49: 2208-2211.

2. Mendelson M, Cloutier J, Spence L, Sellers E, Taback S, et al. (2011) Obesity and type 2 diabetes mellitus in a birth cohort of first nation children born to mothers with pediatric-onset type 2 diabetes. Pediatr Diabetes 12: 219-228.

3. Clausen TD, Mathiesen ER, Hansen T, Pedersen O, Jensen DM, et al. (2009) Overweight and the metabolic syndrome in adult offspring of women with diet-treated gestational diabetes mellitus or type 1 diabetes. J Clin Endocrinol Metab 94: 2464-2470.

4. Hammoud NM, de Valk HW, van Rossem L, Biesma DH, Wit JM, et al. (2017) Growth and BMI during the first $14 \mathrm{y}$ of life in offspring from women with type 1 or type 2 diabetes mellitus. Pediatr Res 81: 342-348. 
5. Hammoud NM, Visser GHA, van Rossem L, Biesma DH, Wit JM, et al. (2018) Long-term BMI and growth profiles in offspring of women with gestational diabetes. Diabetologia 61: 1037-1045.

6. Carolan-Olah M, Duarte-Gardea M, Lechuga J (2015) A critical review: Early life nutrition and prenatal programming for adult disease. J Clin Nurs 24: 3716-3729.

7. McMillen IC, Rattanatray L, Duffield JA, Morrison JL, MacLaughlin SM, et al. (2009) The early origins of later obesity: Pathways and mechanisms. Adv Exp Med Biol 646: 71-81.

8. Morgan K, Rahman M, Atkinson M, Zhou SM, Hill R, et al. (2013) Association of diabetes in pregnancy with child weight at birth, age 12 months and 5 years-a population-based electronic cohort study. PLoS One 8: e79803.

9. Beyerlein A, Nehring I, Rosario AS, von Kries R (2012) Gestational diabetes and cardiovascular risk factors in the offspring: Results from a cross-sectional study. Diabet Med 29: 378-384.

10. Tsadok MA, Friedlander $Y$, Paltiel $O$, Manor $O$, Meiner $V$, et al. (2011) Obesity and blood pressure in 17-year-old offspring of mothers with gestational diabetes: Insights from the Jerusalem Perinatal Study. Exp Diabetes Res.

11. Pirkola J, Pouta A, Bloigu A, Hartikainen AL, Laitinen J, et al. (2010) Risks of overweight and abdominal obesity at age 16 years associated with prenatal exposures to maternal prepregnancy overweight and gestational diabetes mellitus. Diabetes Care 33: 1115-1121.

12. Kubo A, Ferrara A, Windham GC, Greenspan LC, Deardorff $J$, et al. (2014) Maternal hyperglycemia during pregnancy predicts adiposity of the offspring. Diabetes Care 37: 2996-3002.

13. Karp SM, Barry KM, Gesell SB, Po'e EK, Dietrich MS, et al. (2014) Parental feeding patterns and child weight status for Latino preschoolers. Obes Res Clin Pract 8: e88-e97.

14. Chahal H, Fung C, Kuhle S, Veugelers PJ (2013) Availability and night-time use of electronic entertainment and communication devices are associated with short sleep duration and obesity among Canadian children. Pediatr Obes 8: $42-51$.

15. Danner FW (2008) A national longitudinal study of the association between hours of TV viewing and the trajectory of BMI growth among US children. J Pediatr Psychol 33: 1100-1107.

16. Goldfield GS, Kenny GP, Hadjiyannakis S, Phillips P, Alberga AS, et al. (2011) Video game playing is independently associated with blood pressure and lipids in overweight and obese adolescents. PLoS One 6: e26643.

17. Wijga AH, Scholtens S, Bemelmans WJ, Kerkhof M, Koppelman GH, et al. (2010) Diet, screen time, physical activity, and childhood overweight in the general population and in high risk subgroups: Prospective analyses in the PIAMA Birth Cohort. J Obes.

18. Nagel G, Wabitsch M, Galm C, Berg S, Brandstetter S, et al. (2009) Determinants of obesity in the Ulm research on metabolism, exercise and lifestyle in children (URMEL-ICE). Eur J Pediatr 168: 1259-1267.

19. Miller SA, Taveras EM, Rifas-Shiman SL, Gillman MW (2008) Association between television viewing and poor diet quality in young children. Int J Pediatr Obes 3: 168-176.

20. Van Gameren-Oosterom HB, Van Dommelen P, Oudesluys-Murphy AM, Buitendijk SE, Van Buuren $S$, et al. (2012) Healthy growth in children with Down syndrome. PLoS One 7: e31079.
21. Visser $G H$, Eilers PH, Elferink-Stinkens PM, Merkus HM, Wit JM (2009) New Dutch reference curves for birthweight by gestational age. Early Hum Dev 85: 737-744.

22. Cole TJ, Roede MJ (1999) Centiles of body mass index for Dutch children aged $0-20$ years in 1980-a baseline to assess recent trends in obesity. Ann Hum Biol 26: 303-308.

23. Schonbeck $Y$, Talma $H$, van Dommelen $P$, Bakker B, Buitendijk SE, et al. (2011) Increase in prevalence of overweight in Dutch children and adolescents: A comparison of nationwide growth studies in 1980, 1997 and 2009. PLoS One 6: e27608.

24. Cole TJ, Bellizzi MC, Flegal KM, Dietz WH (2000) Establishing a standard definition for child overweight and obesity worldwide: International survey. BMJ 320: 1240-1243.

25. Hermanussen M, Cole $\mathrm{J}$ (2003) The calculation of target height reconsidered. Horm Res 59: 180-183.

26. van Dommelen $P$, Schonbeck $Y$, van Buuren S (2012) A simple calculation of the target height. Arch Dis Child 97: 182.

27. van den Berg SW, Wijga AH, van Rossem L, Gehring U, Koppelman $\mathrm{GH}$, et al. (2015) Maternal fish consumption during pregnancy and $\mathrm{BMI}$ in children from birth up to age 14 years: The PIAMA cohort study. Eur J Nutr 55: 799-808.

28. Rijpert M, Evers IM, de Vroede MA, de Valk HW, Heijnen CJ, et al. (2009) Risk factors for childhood overweight in offspring of type 1 diabetic women with adequate glycemic control during pregnancy: Nationwide follow-up study in the Netherlands. Diabetes Care 32: 2099-2104.

29. Tin SP, Ho SY, Mak KH, Wan KL, Lam TH (2011) Breakfast skipping and change in body mass index in young children. Int J Obes (Lond) 35: 899-906.

30. Kyriazis I, Rekleiti M, Saridi M, Beliotis E, Toska A, et al. (2012) Prevalence of obesity in children aged 6-12 years in Greece: nutritional behaviour and physical activity. Arch Med Sci 8: 859-864.

31. Gleason PM, Dodd AH (2009) School breakfast program but not school lunch program participation is associated with lower body mass index. J Am Diet Assoc 109: 118-128.

32. Gubbels JS, Kremers SP, Stafleu A, Dagnelie PC, de Vries $\mathrm{SI}$, et al. (2009) Clustering of dietary intake and sedentary behavior in 2-year-old children. J Pediatr 155: 194-198.

33. Miller P, Moore RH, Kral TV (2011) Children's daily fruit and vegetable intake: Associations with maternal intake and child weight status. J Nutr Educ Behav 43: 396-400.

34. de Bruijn GJ, Kremers SP, de Vries H, van Mechelen W, Brug J (2007) Associations of social-environmental and individual-level factors with adolescent soft drink consumption: Results from the SMILE study. Health Educ Res 22: 227-237.

35. Holland JC, Kolko RP, Stein RI, Welch RR, Perri MG, et al. (2014) Modifications in parent feeding practices and child diet during family-based behavioral treatment improve child zBMI. Obesity (Silver Spring) 22: 119-126.

36. Fisher JO, Birch LL (1999) Restricting access to foods and children's eating. Appetite 32: 405-419.

37. Gubbels JS, Kremers SP, Stafleu A, de Vries SI, Goldbohm RA, et al. (2011) Association between parenting practices and children's dietary intake, activity behavior and development of body mass index: the KOALA Birth Cohort Study. Int J Behav Nutr Phys Act 8: 18.

38. Hummel S, Pfluger M, Kreichauf S, Hummel M, Ziegler AG 
(2009) Predictors of overweight during childhood in offspring of parents with type 1 diabetes. Diabetes Care 32: 921-925.

39. Rodekamp E, Harder T, Kohlhoff R, Franke K, Dudenhausen JW, et al. (2005) Long-term impact of breast-feeding on body weight and glucose tolerance in children of diabetic mothers: Role of the late neonatal period and early infancy. Diabetes Care 28: 1457-1462.
40. Gubbels JS, Kremers SP, Stafleu A, Dagnelie PC, de Vries NK, et al. (2010) Child-care environment and dietary intake of 2- and 3-year-old children. J Hum Nutr Diet 23: 97-101.

41. Puhl RM, Schwartz MB (2003) If you are good you can have a cookie: How memories of childhood food rules link to adult eating behaviors. Eat Behav 4: 283-293. 